\title{
Politização de controvérsias científicas pela mídia brasileira em tempos de pandemia: a circulação de preprints sobre Covid-19 e seus reflexos
}

\author{
Thaiane OLIVEIRA ${ }^{1}$ \\ Ronaldo Ferreira ARAUJO ${ }^{2}$ \\ Roberta Cardoso CERQUEIRA ${ }^{3}$ \\ Patrícia PEDRI ${ }^{4}$
}

\begin{abstract}
Resumo:
Diante da profusão de preprints durante a pandemia, a proposta do artigo é entender como ocorreu a circulação desses produtos científicos, em especial, nas matérias veiculadas em portais de notícia, quais enquadramentos são utilizados e como essas matérias são percebidas pelos usuários no Facebook. Os procedimentos metodológicos empregados na pesquisa foram a análise de dados bibliográficos, a análise de enquadramento midiático e a escuta social. Os resultados do estudo indicam que 38,6\% das matérias mencionam que a pesquisa divulgada está em processo de avaliação, $27,6 \%$ das notícias omitem essa informação e $19,6 \%$ fazem menções superficiais ou errôneas. Quanto aos enquadramentos, foram identificadas notícias com ênfase nas crises política e epistêmica, e, em menor proporção, em checagem de fatos e construção crítica e explicativa, sendo que todas elas trazem controvérsias científicas como centro da discussão. Como reflexos desses enquadramentos, observa-se a polarização da ciência entre usuários e manifestações de descrença na ciência e na mídia como comportamentos recorrentes.
\end{abstract}

Palavras-chave: ciência aberta; preprints; circulação da comunicação científica; enquadramento midiático; escuta social.

\section{The politicization of scientific controversies by the Brazilian media in times of pandemic: the circulation of preprints on Covid- 19 and its reflexes}

\begin{abstract}
:
Faced with a profusion of preprints during the pandemic, the purpose of the article is to understand how the circulation of these scientific products occurred, particularly in the articles published on news portals, which
\end{abstract}

\footnotetext{
${ }^{1}$ Doutora em Comunicação. Professora do Programa de Pós-Graduação em Comunicação da Universidade Federal Fluminense (UFF).E-mail: thaianeoliveira@id.uff.br.

2 Doutor em Ciência da Informação. Professor do Programa de Pós-Graduação em Ciência da Informação da Universidade Federal de Alagoas (UFAL).E-mail: ronaldo.araujo@ichca.ufal.br.

${ }^{3}$ Doutoranda do Programa de Pós-Graduação em História das Ciências e da Saúde da Casa de Oswaldo Cruz/Fiocruz. Editora executiva de História, Ciências, Saúde - Manguinhos. E-mail: roberta.cerqueira@fiocruz.br.

${ }^{4}$ Mestranda no Programa de Pós-Graduação em Ciência da Informação da Universidade Federal de Alagoas (UFAL).E-mail: patriciapedri@gmail.br.
} 
frameworks are used and how users on Facebook perceive these articles. The methodological procedures used in the research were bibliographic data analysis, media framework analysis and social listening. The study results indicate that $38.6 \%$ of the articles mention that the research published is in the evaluation process, $27.6 \%$ of the news omit this information, and 19.6\% make superficial or erroneous mentions. As for the framings, it was identified news with an emphasis on political and epistemic crises, and to a lesser extent, on fact-checking and critical and explanatory construction, all of which bring scientific controversies at the centre of the discussion. The reflections on the frameworks show the polarization of science between users and manifestations of disbelief in science and the media as recurrent behaviors.

Keywords: open science; preprints; circulation of scientific communication; media framing; social listening.

\section{Politización de las controversias científicas en los medios brasileros en tiempos de pandemia: la circulación de preprints sobre Covid-19 y sus reflejos}

\section{Resumen:}

Frente al aumento de preprints durante la pandemia, la propuesta de este artículo es entender cómo ocurrió la circulación de estos productos científicos, especialmente, en materias divulgadas en portales de noticias, cuáles fueron los encuadramientos utilizados y cómo estas materias son percibidas por los usuarios de Facebook. Los procedimientos metodológicos utilizados en la investigación fueron el análisis de datos bibliográficos, el análisis de encuadre de medios y la escucha social. Los resultados del estudio indican que el 38,6\% de los artículos mencionan que la investigación publicada está en proceso de evaluación, el 27,6\% de las noticias omiten esta información y el 19,6\% hace menciones superficiales o erróneas. En los encuadramientos mediáticos fueron identificadas noticias con énfasis en la crisis política y epistémica, y en menos proporción la verificación y construcción crítica y explicativa, siendo que todas ellas involucran controversias científicas como centro de la discusión. Como reflejo de estas aproximaciones y como comportamiento recurrente se observó una polarización hacia la ciencia entre usuarios y manifestaciones que desacreditan la ciencia y a los medios.

Palabras clave: ciencia abierta; preprints; circulación de la comunicación científica; encuadre de medios; escucha social.

\section{Introdução}

A pandemia do coronavírus provocou um debate já latente na comunidade acadêmica: a urgência de se discutir as limitações do sistema de publicação científica em acesso fechado e as implicações do processo de circulação da comunicação das pesquisas científicas para além da comunidade acadêmica. No momento em que o mundo atravessa mais uma crise sanitária global, os cientistas têm sido cobrados a publicar cada vez mais rápido não apenas os resultados de suas pesquisas, mas também os dados, de maneira aberta.

Diversas instituições, fundações e organizações mundiais têm se posicionado em prol da ciência aberta, apontando-a como uma solução urgente e necessária não apenas para combater a doença e descobrir tratamentos, mas também para enfrentar a desinformação e aumentar a confiança sobre a ciência em um momento de ceticismo da população sobre as 
instituições científicas (THE GLOBAL..., 2019). Como uma das possibilidades postas pelo movimento da ciência aberta, acreditamos que os preprints tornaram-se uma das principais formas de comunicação científica nesse modelo de aceleração da publicação dos resultados da pesquisa.

Ainda que os preprints sejam um reflexo das transformações do sistema de compartilhamento da informação científica, emergido no ecossistema científico global há mais de duas décadas, são inúmeros os desafios relacionados à circulação da informação científica na modalidade. A explosão de servidores de preprints nos últimos dez anos, combinada ao pouco conhecimento sobre práticas científicas junto à sociedade em geral, tem provocado uma série de debates, sugerindo que podem se tornar força perturbadora na comunicação (CHIARELLI; JOHNSON; PINFIELD; RICHENS, 2019) por meio de novas funções atribuídas ao editor científico (LUTHER; ANDERSON; BRADFORD; INGLIS, 2017), que passará a usar os repositórios de pré-impressão como um lago para pesca de artigos com qualidade ou de grande repercussão.

Os preprints consistem em artigos que ainda não passaram pela avaliação entre os pares, prática científica fundamental na qual controvérsias científicas são colocadas em debate junto aos especialistas para validar ou não o conhecimento científico. No entanto, muitos preprints são utilizados como referências não apenas no campo científico, mas também mencionados em debates públicos nas redes sociais e citados na mídia impressa, apesar de ainda não terem sido avaliados e, portanto, enquadrarem-se em um entendimento de que ainda são artigos controversos, o que é parte do sistema democrático do fazer científico. Entender como a mídia enquadra essas publicações e como essas controvérsias são percebidas pela sociedade se torna urgente, quando a deslegitimação das instituições científicas está presente em muitos discursos, inclusive em falas de lideranças mundiais (VERAS, 2020).

É necessário, portanto, entender a circulação dessas produções para além da atenção online que recebem em plataformas de mídias sociais (ARAÚJO; MURAKAMI; PRADO, 2018) e compreender como circulam, suas dinâmicas estruturais próprias nas redes sociais digitais, seus enquadramentos, vieses e posicionamentos nos discursos produzidos pelo jornalista e nos significados construídos no processo comunicativo entre a mensagem e os sujeitos. 
É nesta perspectiva que o trabalho foi desenvolvido, a de compreender como os preprints sobre a Covid-19 circulam na mídia tradicional. Como a mídia enquadra os preprints? As matérias selecionadas neste estudo e que citam os preprints ajudam a enfrentar a desinformação sobre a Covid-19 ou reforçam outros enquadramentos, provocando mais disputas relacionadas à ciência? Estas foram algumas das questões que nortearam a pesquisa e que buscamos responder ao longo do texto.

Ciência aberta e comunicação rápida no enfrentamento da Covid-19 e da desinformação científica

Em janeiro de 2020, a fundação Wellcome Trust fez um apelo para que cientistas, periódicos científicos e financiadores garantissem a publicação rápida e aberta dos resultados e dos dados de pesquisa sobre a Covid-19, com o intuito de combatê-la e colaborar com a saúde pública. Em seu portal foi divulgada uma lista de editoras que aderiram à declaração (WELLCOME, 2020), entre elas empresas que fazem parte do oligopólio editorial científico, com um lucrativo modelo de negócios baseado na comercialização do acesso fechado, acordos com bibliotecas institucionais e a cobrança de taxas de publicação para acesso aberto.

A Organisation for Economic Co-operation and Development (OECD) ${ }^{5}$ afirmou, em maio de 2020, que em emergências globais como a pandemia da Covid-19, as políticas de ciência aberta podem remover obstáculos ao fluxo livre de dados e ideias de pesquisa e, assim, acelerar o ritmo da pesquisa crítica para combater a doença. Destacou que lições de surtos anteriores ressaltaram a importância de compartilhar dados, facilitando o compartilhamento para construir e manter a confiança entre as partes.

Outros movimentos marcam a trajetória de como a ciência aberta tem se desdobrado neste cenário de pandemia. Um deles ocorreu em janeiro de 2020, no qual 117 organizações assinaram uma declaração intitulada "Compartilhando dados de pesquisa e descobertas relevantes para o novo surto de coronavírus", comprometendo-se a fornecer acesso aberto imediato a publicações revisadas por pares, ao menos durante o surto, por meio de servidores de pré-impressão, a fim de compartilhar os resultados imediatamente com a Organização Mundial da Saúde (OMS) (SHARING, 2020). Isto foi seguido em março pelo Public Health

\footnotetext{
${ }^{5}$ Organização para a Cooperação e Desenvolvimento Econômico (OCDE).
} 
Emergency COVID-19 Initiative, lançada por 12 países no nível de conselheiros-chefes de ciências ou equivalente, exigindo acesso aberto a publicações e acesso legível, por máquina, a dados relacionados a Covid-19, resultando em compromisso ainda mais forte por parte dos editores.

Para além de um movimento de fundações e do próprio mercado editorial científico em prol da celeridade da publicação dos resultados das investigações, nos EUA, o então presidente Donald Trump decretou que as revistas liberassem seus conteúdos relacionados à pandemia. Em março, conselheiros científicos de doze países, ${ }^{6}$ por intermédio do Office of Science and Technology Policy da Casa Branca, divulgaram uma declaração solicitando aos editores que suas publicações sobre o coronavírus fossem disponibilizadas rapidamente no PubMed Central ou em outros repositórios públicos (THE WHITE HOUSE, 2020). Editoras comerciais como a Springer Nature, a Elsevier, a Wiley e a Taylor-Francis foram impulsionadas a também disponibilizarem seus artigos. No Brasil, apesar de ser considerado uma das lideranças em acesso aberto no mundo (SCIENCE-METRIX, 2018), esses esforços estão sendo encabeçados pelas próprias instituições e organizações científicas.

Além de discursos que se relacionam com uma abordagem produtivista da ciência aberta, no qual aceleração, transparência, cooperação e reprodutibilidade são valores recorrentes nas falas institucionais, um outro discurso emerge trazendo a ciência aberta, sobretudo a comunicação da ciência aberta, como solução para um dos grandes desafios dos ecossistemas informacionais: a desinformação científica. No entanto, quando falamos de comunicação da ciência, entendemos não só a comunicação interpares, mas também a comunicação pública da ciência (EPSTEIN, 2012). A comunicação científica abrange toda cadeia de comunicação focada na ciência, no trabalho científico e em seus resultados (SCHÄFER; KRISTIANSEN; BONFADELLI, 2015). Portanto, inclui a comunicação sobre a produção científica para não cientistas, seja pelos próprios cientistas ou mediada pela mídia jornalística, que se coloca como uma guardiã dos interesses do público, com a tarefa de controle

\footnotetext{
${ }^{6}$ Os doze países que elaboraram o documento dirigido à comunidade de editores científicos foram Austrália, Alemanha, Brasil, Canadá, Estados Unidos, Itália, Índia, Japão, Coreia do Sul, Nova Zelândia, Reino Unido e Singapura (THE WHITE HOUSE, 2020).

${ }^{7}$ O PubMed Central é um repositório digital de artigos científicos das ciências da vida e biomédicas em acesso aberto desenvolvido pelo National Center for Biotechnology Information (NCBI), que é uma divisão da United States National Library of Medicine (NLM), órgão do National Institutes of Health (PUBMED OVERVIEW, s.d.).
} 
de qualidade e veracidade informacional, atuando como um gatekeeper da informação científica (WEINGART; GUENTHER, 2016) e definindo o que será noticiado de acordo com o valornotícia, linha editorial e outros critérios.

De acordo com Schäfer, Kessler e Fähnrich (2019), os estudos sobre a comunicação da ciência passaram por uma série de estágios, que vai desde o modelo de déficit, já muito superado nesses estudos, até o engajamento público com modelos científicos em que não-cientistas eram vistos como iguais parceiros na ciência. Com base em Akin e Scheufele (2017), é possível identificar um terceiro momento atual, que corresponde a uma era de comunicação pública nas democracias modernas, na qual a comunicação científica é moldada por seus ambientes sociais e políticos, levando-nos a discutir as implicações éticas, sociais ou políticas dessa forma de se comunicar a ciência mediada por empresas jornalísticas, sobretudo em um contexto de politização e polarização relacionada à Covid-19 (HART; CHINN; SOROKA, 2020). Isso traz questões sobre o papel que a mídia tem desempenhado na ampliação da politização e polarização do novo coronavírus, já que esse tipo de cobertura jornalística pode influenciar as atitudes públicas e exacerbar as tensões político-ideológicas, contribuindo para um processo de disputa sobre a informação e desinformação relacionada à ciência

\section{O desafio do jornalismo científico: entre a escuta e construção da crítica}

O conceito de desinformação é um campo de disputa epistêmico, no qual a contestação da informação é uma forma de se legitimar como autoridade sobre a veracidade informacional (OLIVEIRA, 2020). O discurso de autolegitimação de autoridade epistêmica tem sido proferido por instituições científicas e jornalísticas como forma de reforçar a sua própria autoridade como instituições produtoras ou disseminadoras de conhecimento e informação. Essa forma de se posicionar e se legitimar como autoridade pode ser entendida como uma defesa corporativa em um momento de contestação epistêmica, reforçando a ideia de que um conjunto de convenções sociais de noticiabilidade (como a neutralidade, a objetividade e a imparcialidade) é capaz de cumprir o dever social do jornalismo, sobretudo o científico, o de informar ao cidadão. No entanto, como já apontava Dias e Almeida (2009, p. 4401-3), “a função do jornalista científico não se restringiria apenas em informar, mas comunicar a ciência jornalisticamente implicaria em comunicar de forma crítica, situada, contextual e rigorosa". 
Tais discursos de autolegitimação de instituições epistêmicas, como o Jornalismo, na condição de instância de confiança sobre a produção da verdade, vai de encontro às tradições nos campos dos estudos de Comunicação e Jornalismo, que remontam à década de 1970 (FISHMAN, 1980; TUCHMAN, 1978). Essas análises partem de um entendimento de que a notícia é um produto socialmente construído, e o jornalismo ocidental, a partir de modelos anglo-americanos de produção de notícia (TAVARES, 2019), utiliza convencionalmente uma estratégia retórica que inebria escolhas do jornalista ou da empresa jornalística para a qual ele trabalha. É nesse sentido que um conjunto de conceitos do campo da Comunicação se torna relevante para entender as disputas sobre a produção de notícia relacionada à ciência, entre eles o de enquadramento. Como Tuchman (1978, p. 1) já indicava na década de 1970, as notícias são como janelas que "pretendem dar-nos aquilo que queremos saber, necessitamos de saber e devemos saber". No entanto, os vidros das "janelas" de notícias podem delimitar a nossa visão sobre o mundo. O enquadramento, como apresentou Tuchman (1978) e Gitlin (2003), não se processa de forma ideologicamente neutra, por mais que escolhas sobre convenções narrativas sejam adotadas, como o modelo anglo-americano de produção de notícia, utilizado pelo jornalismo brasileiro (ALBUQUERQUE, 2004).

Entender como esses enquadramentos influenciam na interpretação dos leitores é um grande desafio. Um dos caminhos para isso é a escuta social, ouvir o que os usuários dizem, suas recorrências discursivas manifestadas na interação entre a mensagem e o leitor. Segundo Young, Simmons e Stewart (2019), a escuta social é um tipo emergente de procedimento baseado na escuta para obter informações interpessoais e inteligência social, revelando estratégias para fortalecer relacionamentos e influenciar o processo comunicacional. Atentarse e ouvir quais são os discursos recorrentes dos usuários em determinados enquadramentos da notícia pode nos fornecer importantes pistas de como os sujeitos se relacionam com as matérias que mencionam artigos ainda, não avaliados, sobretudo quando a mídia politiza e polariza o debate sobre a ciência.

\section{Metodologia}

Ao buscar a compreensão de como a comunicação rápida dos preprints sobre a Covid é retratada na mídia brasileira, e se tal enquadramento auxilia no enfrentamento da desinformação 
ou, de outra maneira, acaba por acirrar disputas relacionadas à ciência, a pesquisa adota procedimentos metodológicos mistos complementares (JOHNSON; ONWUEGBUZIE; TURNER, 2007) que se desdobram a partir das seguintes etapas:

(a) Pesquisa bibliográfica na identificação e seleção de um conjunto de preprints sobre a Covid-19. A fonte de dados adotada nesta etapa foi a base Dimensions, utilizada por meio de consultas realizadas em 23 de setembro de 2020 pelos termos/expressões de busca: "covid19 OR covid-19 OR covid2019 OR sars-cov-2 OR sars cov 2 OR coronavirus" presentes em títulos e palavras-chave, considerando todos os preprints de 2020. Dentre os repositórios de preprints presentes na base, levamos em consideração para análise na próxima etapa o que obteve maior número de registros, a saber, o medRxiv, com total de 6.949 pesquisas.

(b) Análise altmétrica de cobertura midiática dos preprints. Extração de dados do Dimensions e mapeamento da circulação dos preprints na mídia brasileira. Para esta etapa foi gerado um arquivo .csv com os metadados dos preprints. Desse arquivo foi importado para a ferramenta Altmetric Explorer a lista dos Digital Object Identifier (DOI) de cada preprint e aplicado os filtros: menções apenas para "mídia" (news) e oriundas do Brasil (from Brazil).

(c) Tipificação de acesso e grau explicativo dos preprints nas matérias. Nesta etapa, por meio da análise de conteúdo, cada matéria foi visitada para identificar: o tipo de acesso (aberto ou restrito-apenas para assinante) e o nível de explicação dada às particularidades da comunicação rápida da pesquisa. Para esta questão foram considerados quatro níveis explicativos, presentes no Quadro 1, com suas respectivas descrições. 
Quadro 1 - Categorias ou níveis de apresentação dos preprints nas notícias

\begin{tabular}{|l|l|}
\hline Categorias/níveis & Descrição \\
\hline Informativo & $\begin{array}{l}\text { Esclarece que a pesquisa está em processo de revisão ou avaliação. } \\
\text { Menciona que ainda não foi publicada em revista científica. }\end{array}$ \\
\hline Superficial & $\begin{array}{l}\text { Menciona tratar-se de preprint, pré-impressão ou similar, mas sem } \\
\text { esclarecer o que isso significa. }\end{array}$ \\
\hline Incoerente & $\begin{array}{l}\text { Emprega erroneamente a relação do preprint quanto ao estágio de validade } \\
\text { da pesquisa. Apresenta como publicado ou denomina o servidor preprint } \\
\text { de revista. }\end{array}$ \\
\hline Inexistente & Não faz nenhuma menção ao fato de se tratar de um preprint. \\
\hline Inacessível & Matérias com modalidade de acesso restrito a assinantes. \\
\hline
\end{tabular}

Fonte: elaborado pelos autores (2020).

(d) Análise sobre o enquadramento midiático do artigo científico de maior menção na mídia a partir dos dados coletados nas etapas anteriores. Para tanto, a análise de enquadramento é apresentada a partir de uma perspectiva construtivista, para examinar o discurso das notícias com o foco principal na conceituação de textos de notícias nas dimensões de estruturas de abordagem narrativa e construção retóricas.

(e) Análise da repercussão das matérias nas redes sociais. Utilizando escuta social, nesta etapa buscou-se identificar os principais discursos relacionados à ciência a partir da interação do usuário com as matérias coletadas nas etapas anteriores, acompanhando a circulação e interação em torno de suas URLs com foco no Facebook. Para isso, foi utilizado o CrowdTangle, ferramenta que possibilita analisar e relatar o que está acontecendo com o conteúdo público em redes sociais, para compreender como as mensagens relacionadas à ciência são entendidas pelo sujeito e que discursos sobre ciência emergem na interação com o texto.

\section{Resultados}

Os resultados são descritos primeiramente a partir da análise de dados sobre preprints e circulação na mídia, e, em seguida, o grau explicativo das matérias e os enquadramentos das narrativas identificadas. 


\section{Análise de dados sobre preprints e circulação na mídia}

Os resultados desta pesquisa indicam que dos 6.949 preprints pertencentes ao repositório medRxiv, apenas $181(2,6 \%)$ deles foram mencionados em ao menos uma matéria de portais brasileiros de notícia on-line. Foram identificadas, ao todo, 453 notícias, publicadas por 56 fontes que podem ser vistas na Tabela 1, com indicação nominal das que publicaram mais matérias (10 ou mais).

Tabela 1 - Principais fontes de notícia com menções a preprints sobre Covid-19

\begin{tabular}{clrr}
\hline \# & Fonte de noticias & Matérias & (\%) \\
1 & G1 & 67 & 14,8 \\
2 & UOL & 53 & 11,7 \\
3 & Replicário & 36 & 7,9 \\
4 & Bol & 35 & 7,7 \\
5 & Superinteressante & 24 & 5,3 \\
6 & Estadao.com.br & 23 & 5,1 \\
7 & Galileu & 23 & 5,1 \\
8 & Canaltech & 21 & 4,6 \\
9 & Metrópoles & 20 & 4,4 \\
10 & Agência Fapesp & 18 & 4,0 \\
11 & Olhar Digital & 11 & 2,4 \\
12 & MixVale & 11 & 2,4 \\
13 & Pesquisa Fapesp & 10 & 2,2 \\
- & Portais com menos de 10 matérias (43) & 101 & 22,3 \\
& Total Geral & $\mathbf{4 5 3}$ & $\mathbf{1 0 0}$ \\
& & &
\end{tabular}

Fonte: dados da pesquisa (2020).

Há uma concentração de notícias em um grupo menor de fontes, uma vez que as cinco primeiras listadas na Tabela 1 concentram 47,5\% das matérias. Os portais G1 e UOL se destacam em número de matérias, com 67 (14,8\%) e 53 (11,7\%) notícias, respectivamente. Um conjunto de 43 veículos publicou até nove matérias (22,3\%). Desses 43, 19 publicaram apenas uma matéria $(4,1 \%)$.

De igual modo, buscou-se analisar os preprints com maior circulação entre as mídias brasileiras, noticiados com maior frequência que os demais. A Tabela 2 apresenta o ranking das 
principais pesquisas e o indicativo do número de matérias que elas receberam. Os preprints com menos de sete notícias foram computados, mas não estão nominados.

Tabela 2 - Preprints sobre Covid-19 mais noticiados pela mídia brasileira

\begin{tabular}{|c|c|c|c|}
\hline$\#$ & Titulo do preprint & Matérias & (\%) \\
\hline 1 & $\begin{array}{l}\text { Chloroquine diphosphate in two different dosages as adjunctive } \\
\text { therapy of hospitalized patients with severe respiratory syndrome } \\
\text { in the context of coronavirus (SARS-CoV-2) infection... }\end{array}$ & 16 & 3,5 \\
\hline 2 & $\begin{array}{l}\text { Aerosol and surface stability of HCoV-19 (SARS-CoV-2) } \\
\text { compared to SARS-CoV-1 }\end{array}$ & 14 & 3,1 \\
\hline 3 & Evolution and epidemic spread of SARS-CoV-2 in Brazil & 13 & 2,9 \\
\hline 4 & $\begin{array}{l}\text { Epidemiological and clinical characteristics of the early phase of } \\
\text { the COVID-19 epidemic in Brazil }\end{array}$ & 12 & 2,6 \\
\hline 5 & $\begin{array}{l}\text { In vivo demonstration of microvascular thrombosis in severe } \\
\text { Covid-19 }\end{array}$ & 9 & 2,0 \\
\hline 6 & $\begin{array}{l}\text { Herd immunity thresholds for SARS-CoV-2 estimated from } \\
\text { unfolding epidemics }\end{array}$ & 9 & 2,0 \\
\hline 7 & $\begin{array}{l}\text { Relationship between the ABO Blood Group and the COVID-19 } \\
\text { Susceptibility }\end{array}$ & 9 & 2,0 \\
\hline 8 & $\begin{array}{l}\text { A Bayesian reanalysis of the effects of hydroxychloroquine and } \\
\text { azithromycin on viral carriage in patients with COVID- } 19\end{array}$ & 9 & 2,0 \\
\hline 9 & $\begin{array}{l}\text { Heparin therapy improving hypoxia in COVID-19 patients - a case } \\
\text { series }\end{array}$ & 8 & 1,8 \\
\hline 10 & $\begin{array}{l}\text { Demand for hospitalization services for COVID-19 patients in } \\
\text { Brazil }\end{array}$ & 7 & 1,5 \\
\hline - & Preprints mencionados em menos de 7 matérias (211) & 347 & 76,6 \\
\hline & Total Geral & 453 & 100 \\
\hline
\end{tabular}

Fonte: dados da pesquisa (2020).

Um grupo pequeno de preprints foi mais noticiado e um grande volume deles registrou número bem reduzido de matérias. As pesquisas que ocupam os dez primeiros lugares concentram 23,4\% das matérias, enquanto um grupo maior de 211 preprints recebeu entre $1 \mathrm{e}$ 6 matérias (76,6\%). Dessas, 87 preprints foram mencionados em apenas uma matéria $(19,2 \%)$. O primeiro lugar, que merece destaque entre os preprints pelo número de matérias $(n=16$; $3,5 \%$ ), apresenta resultados preliminares de segurança de um ensaio clínico randomizado e duplo-cego. Nele, os autores Borba e outros (2020) relatam a aplicação de difosfato de 
cloroquina em duas dosagens diferentes como terapia adjuvante de pacientes hospitalizados com Síndrome Respiratória Grave no contexto de infecção por coronavírus (SARS-CoV-2).

\section{Enquadramento e escuta social}

O estudo buscou tipificar o grau explicativo dos preprints nas matérias, no sentido assinalado por Dias e Almeida (2009), no qual o jornalista científico, além de informar, precisa comunicar a ciência de forma contextual e rigorosa. O Gráfico 1 indica como as matérias lidam com a questão.

Gráfico 1 - Grau explicativo em que os preprints são apresentados nas notícias

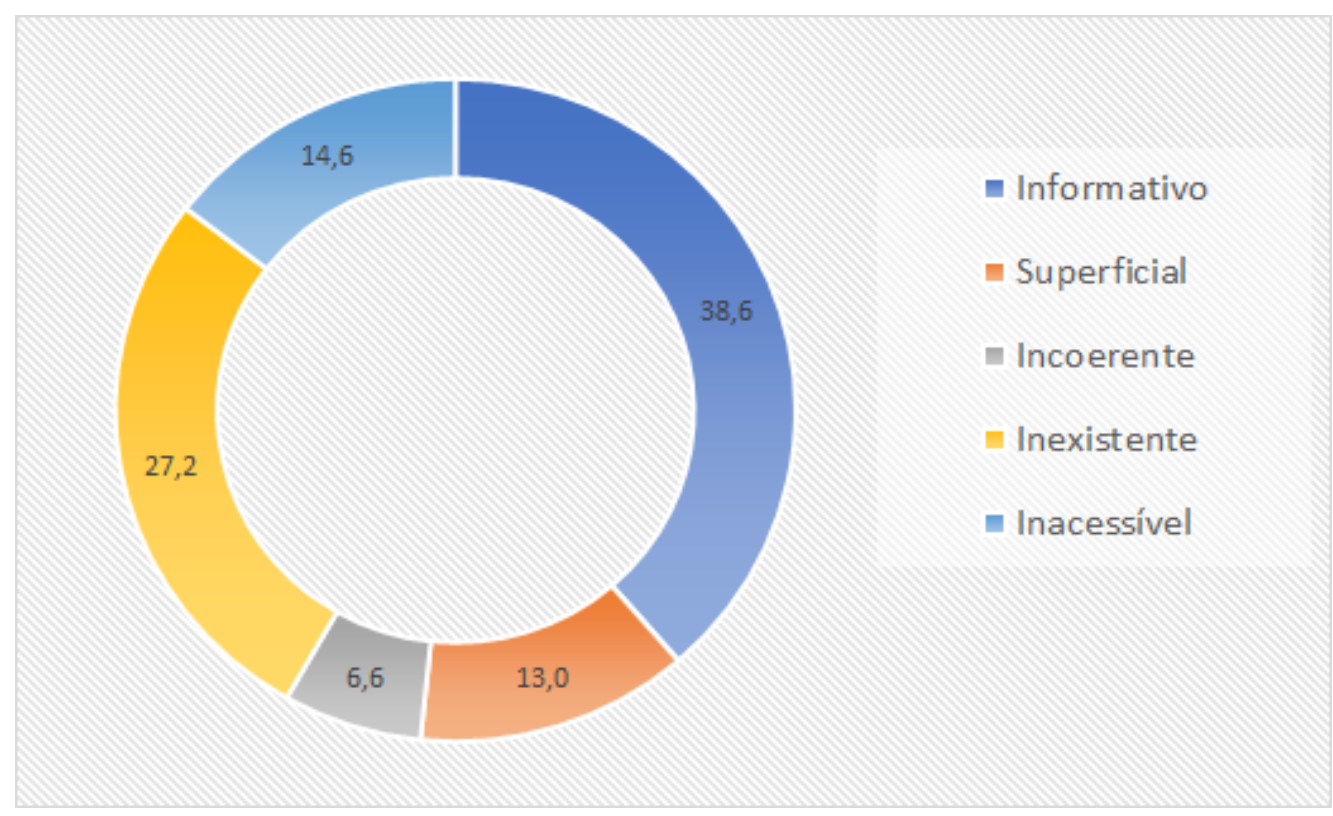

Fonte: dados da pesquisa (2020).

Em 38,6\% das matérias foi observado um grau Informativo, pois esclarecem em alguma medida que a pesquisa divulgada ainda se encontra em processo de revisão ou avaliação pelos pares, e, por isso, não foi publicada em revista científica; enquanto $27,6 \%$ das notícias não informam sobre a pesquisa ser um preprint (Inexistente). A menção ao preprint, pré-impressão ou similar, mas sem informações sobre o que representam para a pesquisa científica, também foi observada (Superficial - 13\%); bem como seu emprego de forma errônea (Incoerente $6,6 \%)$. Na categoria Inacessível $(14,6 \%)$, a maior incidência $(10,8 \%)$ foi para matérias com 
paywall de acesso restrito aos assinantes, e, em menor proporção, para link quebrado ou página não encontrada.

Para a fase seguinte desta pesquisa, selecionamos o artigo mais noticiado, que obteve o primeiro lugar no ranking da Tabela 2. O artigo "Chloroquine diphosphate in two different dosages as adjunctive therapy of hospitalized patients with severe respiratory syndrome in the context of coronavirus (SARS-CoV-2) infection: preliminary safety results of a randomized, double-blinded, phase IIb clinical trial (CloroCovid-19 Study)", de autoria de pesquisadores brasileiros (BORBA et al, 2020), relata os problemas derivados do uso de uma dosagem máxima de hidroxicloroquina, recomendada por pesquisadores chineses e franceses, para tratamento da Covid-19. O artigo foi mencionado por 231 matérias de 164 veículos em diversos países.

No Brasil, o preprint foi mencionado em 16 matérias de 07 canais: UOL, Bol, Catraca Livre, Estadão, CanalTech, Correio do Povo, MS Notícias. Contudo, 08 matérias foram excluídas da análise: 04 matérias possuíam restrições de acesso (acesso apenas para assinantes) e outras 04 se repetiram - a matéria "Coronavírus: o que dizem os estudos publicados sobre cloroquina, defendida por Bolsonaro e Trump" se repetiu no Uol e Bol; e houve ainda o mesmo texto sob os títulos "Pesquisa brasileira não usou doses letais para matar pacientes e atacar cloroquina" no Correio do Povo, Bol e Estadão) e "Texto sobre pesquisa com doses letais para tirar mérito da cloroquina é falso" no MS Notícias. Dos textos restantes (08), é possível agrupar os enquadramentos narrativos em: ênfase na crise política $(n=04)$, ênfase na crise epistêmica $(n=02)$; checagem de fatos $(n=01)$ e construção crítica e explicativa $(n=01)$. Todas elas trazem controvérsias científicas, em alguma medida, como centro da discussão.

\section{Crise política}

Dos oito textos, quatro enfatizam mais a crise política do que a crise sanitária e os avanços nas discussões científicas. Trazem em seus títulos menções a políticos nacionais e internacionais, como Jair Bolsonaro e Donald Trump, além de outros atores do cenário político, como Luiz Henrique Mandetta e Nelson Teich, ex-ministros da saúde. Títulos como "Coronavírus: o que dizem os estudos publicados sobre cloroquina, defendida por Bolsonaro e Trump" (Uol e Bol) e "Bolsonaro e Teich discordam sobre cloroquina: o que dizem os estudos?" 
(Uol) são exemplos de como o enquadramento em torno da crise política é evidenciado no título das matérias analisadas. Destaques para as falas dos dois líderes mundiais também são evidenciados, como um tweet do presidente Bolsonaro em que apoia o uso da cloroquina, com a expressão de que ele, assim como Donald Trump "também passou a usá-la como tábua de salvação para justificar a volta à vida normal” (O QUE SE SABE..., 2020).

Os lides das matérias trazem para o início um contexto de politização da ciência, com ênfase na crise política, sobretudo em relação à troca de ministros da saúde. Apesar disso, menções sobre controvérsias científicas sobre o uso da cloroquina aparecem ao longo do texto, que tende a apresentar uma série de estudos preliminares e contraditórios, dando espaço para pesquisas que não tiveram aprovação de comitês de éticas ou que foram descartadas pela própria comunidade científica, ao usar metodologias inapropriadas para o rigor científico (GRANCHI, 2020). Por exemplo, o Uol ressalta que "há tantos estudos e confusão sobre eles, que um levantamento feito por pesquisadores dos Estados Unidos e Canadá analisou justamente os estudos que já existem sobre a eficácia e segurança dos medicamentos contra a covid-19. [...] Concluiu que a metodologia usada até agora tem sido 'muito pobre"' (GRAGNANI, 2020, não paginado).

Mencionam também a questão da politização sobre a cloroquina num contexto reforçado pela fala de uma autoridade científica: "a politização da cloroquina dá às pessoas 'falsa esperança' e a sensação de que há um bom tratamento ou um bom medicamento pode fazer com que não tomem as mesmas precauções que tomariam” (GRAGNANI, 2020, não paginado). Frases como “os estudos dividem a comunidade científica” (O QUE SE SABE..., 2020, não paginado) são recorrentes, enquadrando a falta de consenso sobre a pesquisa no Brasil e no mundo em relação à eficácia e segurança, apesar de a cloroquina ser "usada há mais de 70 anos contra a malária" (PESQUISADORES..., 2020, não paginado).

As interações nas 11 páginas que compartilharam as quatro matérias apontam para uma polarização e politização da ciência, em que, de um lado, reforçam a importância e manifestam sua confiança na ciência e, de outro, além de contestarem os dados e achados de pesquisa, manifestam posicionamentos em favor de atores políticos, sobretudo o presidente Bolsonaro. Por exemplo, usuários disseram: "Entre, 2 ex ministros da saúde, medicos, renomados, estudiosos e o Bolsonaro que só briga...Fico com a ciência, educação e a medicina. Minha 
opnião" e "Hoje. depois de tanta esteria da duplinha dinâmica do mal Trump-Bozo dizendo que essa droga era a cura... mas mesmo assim as mortes só crescendo pelo mundo... fico com uma nota da Fiocruz... 'a croraquina não cura nada"'. Entre as interações, é comum encontrar embates entre usuários da rede, nos quais acusações de "gado", "robôs" e "bozolóides", de um lado, "esquerdistas", petistas como "burros", de outro, entre xingamentos a Marielle Franco e contestação a posicionamentos do ex-ministro Mandetta, são o centro da discussão. Contestação às pesquisas e à fonte da matéria também estão presentes, como "os números que aponta este estudo está mal explicado. Continuo acreditando nas pesquisas que mostram os resultados claramente positivo. E em fontes mais confiáveis que UOL".

\section{Crise epistêmica}

Outra recorrência de enquadramento diz respeito à crise epistêmica, em que matérias enfatizam a descrença sobre a ciência, seja a partir da fala de atores que tiveram alguma influência no debate público sobre cloroquina e hidroxicloroquina, como a imunologista e oncologista Nise Yamaguchi (INGRID, 2020), seja pela fala de sujeitos - no caso, segundo o jornal, "militantes do presidente Bolsonaro" ((CIENTISTAS..., 2020, não paginado), 2020). A matéria que traz Nise Yamaguchi como personagem central da notícia dá destaque para a fala da médica, na qual desmerece o investimento em estudos científicos sobre a medicação: “A cloroquina em doses altas a gente sabe que mata, nem precisa desses estudos" (INGRID, 2020, não paginado). Já a matéria do Catraca Livre se desdobra em torno dos ataques a cientistas: "Filho da puta maldito. Deve ser espancado quando pisar na rua!!" e "Assassino comunista fdp" foram algumas das mensagens recebidas pelo médico Marcus Lacerda (CIENTISTAS..., 2020, não paginado). A matéria do $U o l$ teve maior repercussão em redes sociais, tendo sido compartilhada em 18 perfis no Facebook, inclusive nos perfis do próprio portal.

Nesse tipo de enquadramento, os usuários contestam a pesquisa e colocam em dúvida questões éticas dos cientistas. Por exemplo, afirmam: "Fizeram merda no estudo, dando doses cavalares de um medicamento do qual se sabe os efeitos colaterais, muito acima das doses recomendadas. Ou seja, amplificaram os efeitos colaterais propositadamente. Isso é o que?” e "Perfeito, há vários dias já havia o consenso de que altas doses não aceleravam a cura e sim agravavam problemas cardíacos. Continuaram para validar os estudos, então propositadamente 
mataram cobaias 'a bem da ciência"”, Os ataques à ciência também são atravessados por ataques à mídia nesse tipo de enquadramento: "meu Deus do céu, vc tá desinformada demais. Pesquise sobre Didier Raoult e os resultados de suas pesquisas. A mídia quer que vc pense exatamente assim. Ninguém disse que é a cura, mas é o que se tem no momento. O que ele diz não é verdade absoluta, mas ele visa a verdade, enquanto a mídia visa seus próprios interesses" e "Por essa e por outras que a imprensa anda tão desacreditada". O enquadramento sobre descrença epistêmica em torno da instituição científica também se espelha sobre a mídia e a crítica aos enquadramentos midiáticos em questão "vcs nem jornalistas são, jornalista dá noticias, apresenta os fatos, vcs espalham mentiras, boatos e fofocas denigrindo a imagem de quem lhes convém entre vocês da UOL e a cloroquina, acredito na cloroquina de olhos fechados". Os usuários tendem a mostrar um comportamento seletivo, que independe do argumento, corroborado com outros estudos que apontam a dissonância cognitiva como fator emocional, indicando o desenvolvimento de estratégias de enfrentamento à desinformação baseadas em diálogo e comportamento aberto, como a busca de contra-argumentos (TADDICKEN; WOLF, 2020; MONARI, SANTOS, SACRAMENTO, 2020).

\section{Checagem de fatos}

Há também o uso do formato de checagem de fatos baseado em uma construção narrativa de objetividade, neutralidade e imparcialidade adotado pelo jornalismo, como o produzido pelo projeto Comprova e replicado por outros jornais e portais de notícias, como Correio do Povo, Bol, Estadão e MS Notícias, para apresentar como falsas as acusações de que os cientistas que conduziram o estudo no Amazonas teriam modificado a dosagem de propósito para fins políticos, para desvalidar as decisões governamentais sobre o uso da hidroxicloroquina no tratamento à Covid-19.

Entretanto, esse modelo retórico anglo-americano de autolegitimação de produção de verdade por meio da imparcialidade e neutralidade, utilizado pelas agências de checagem, enfatiza a relação de um dos pesquisadores acusados de envolvimento com partidos políticos de esquerda e a controvérsia em relação ao estudo. A matéria de checagem de fatos aponta que "Embora não existam ainda evidências conclusivas sobre a eficácia da cloroquina na cura da Covid-19, alguns trabalhos indicam que o medicamento pode aliviar quadros graves da doença" 
e enfatiza o caráter polarizado sobre o debate (PESQUISA..., 2020, não paginado). Apesar de compartilhada por quatro jornais ou portais de notícias, não houve repercussão dessa matéria no Facebook.

\section{Jornalismo científico crítico e explicativo}

Por fim, destaca-se um outro enquadramento, que apesar de não mencionar que o estudo ainda se encontra em avaliação, informando apenas que está em um repositório de preprint, narra o processo científico, enquadrando as escolhas, impasses e decisões da equipe médica, dando voz ao próprio pesquisador sobre a investigação e aciona uma outra pesquisadora não envolvida com o estudo, a cientista Natália Pasternak, para dar seu posicionamento sobre o artigo. A matéria foi publicada pelo CanalTech, sob o título "COVID-19 no BR: efeitos colaterais interrompem parte de estudo sobre cloroquina", e assinada por Fidel Forato. Não houve repercussão desse estudo no Facebook.

\section{Considerações finais}

Veículos de informação tradicionais como jornais, tanto em seu formato eletrônico, quanto o televisivo, tiveram papel relevante na crise sanitária. Esses canais se mostraram como fontes consolidadas às quais a população tem recorrido para se informar sobre a Covid-19 e suas consequências. Pesquisa realizada pela Universidade Federal do Espírito Santo (ZANETTI; REIS, 2020) verificou o aumento do consumo de notícias durante a pandemia, com os brasileiros e brasileiras buscando, em primeiro lugar $(81,46 \%)$ por notícias sobre a atuação do governo federal em relação à doença; em segundo lugar $(73,89 \%)$, sobre a divulgação de descobertas científicas; e, em terceiro lugar $(72,32 \%)$, sobre quais as recomendações de prevenção contra o coronavírus.

No Brasil, a mídia ainda atuou em outra frente, a de promoção diária dos dados sobre a Covid-19, como número de casos, mortes e regiões mais afetadas pelo vírus. Motivados pelo término dos boletins diários com os informes da doença e a dificuldade em acessar os dados mais atuais, um consórcio de veículos da mídia (Uol, O Estado de S. Paulo, Folha de S. Paulo, $O$ Globo, Gl e Extra) se constituiu para informar os dados mais atualizados à população diariamente, desde junho de 2020. 
As descobertas científicas como um dos aspectos mais buscados nas mídias deram destaque ao trabalho de cientistas e à publicação dos seus resultados de pesquisa, mobilizando jornalistas a divulgarem em suas matérias os artigos e textos científicos sobre a Covid-19. Muitos deles revelaram estudo ainda em construção, os preprints, objeto deste artigo.

É importante destacarmos alguns aspectos que limitaram nosso trabalho. O primeiro deles foi a pesquisa ter se concentrado nos textos pertencentes ao repositório MedRxiv. O segundo diz respeito à relação entre o baixo registro de matérias associadas aos preprints sobre Covid-19 no Brasil e a baixa cobertura altmétrica de fontes de notícias provenientes de países de língua não inglesa indexadas pelas ferramentas agregadoras de dados de altmetria (ORTEGA, 2020).

Neste trabalho, podemos verificar pouca menção ao uso de preprints na elaboração das matérias jornalísticas, com $38,6 \%$ das notícias informando a natureza das pesquisas. O número considerável de matérias que não mencionam o uso desse modelo de publicação ou mesmo informam de maneira superficial acende-nos o alerta sobre como os resultados das investigações científicas estão sendo divulgados. Contudo, para além dos aspectos formais, deve ser ressaltado que os enquadramentos do jornalismo trazem para o plano de discussão uma politização de controvérsias científicas e ênfase sobre crise epistêmica, reforçando uma percepção crescente de ceticismo científico junto à população. Nesse sentido, os preprints selecionados permitiram a análise a partir de agrupamentos narrativos que enfatizaram a crise política, a crise epistêmica, a checagem dos fatos e a construção crítica e explicativa. Em um momento de crise epistêmica proliferam narrativas de teorias da conspiração que atacam não apenas a legitimidade de pesquisas e instituições, mas também se esbarram com recorrências discursivas dos que colocam em dúvida a atuação da mídia sobre os enquadramentos adotados pelos jornalistas. Isso nos levando a refletir sobre a própria responsabilidade do jornalismo no processo de descredibilização de sua autoridade.

Ao chamar atenção sobre determinado estudo em construção que ainda não poder ser considerado uma pesquisa de resultados definitivos, como é o caso dos preprints, há uma contribuição para a construção do entendimento de como a prática científica se desenvolve em meio a controvérsias, especialmente diante de uma doença desconhecida como o novo coronavírus. 


\section{Referências}

AKIN, Heather; SCHEUFELE, Dietram A. Overview of the science of science communication. The Oxford handbook of the science of science communication, p. 25-33, 2017. Disponível em: https://www.oxfordhandbooks.com/view/10.1093/oxfordhb/9780190497620.001.0001/oxford hb-9780190497620-e-3. Acesso em: 10 set. 2020.

ALBUQUERQUE, Afonso de. A Identidade jornalística no Brasil: algumas questões teóricas e metodológicas. E-Compós, v. 1, 26 jun., p. 1-14, 2004. Disponível em: https://www.ecompos.org.br/e-compos/article/view/17/18. Acesso em: 10 set. 2020.

ARAÚJO, Ronaldo F.; MURAKAMI, Thiago R. M.; PRADO, Jorge Moisés K. do. A repercussão de artigos de periódicos brasileiros da ciência da informação no Facebook. RDBCI - revista digital de biblioteconomia e ciência da informação, v. 16, n. 2, p. 365379, 19 set. 2020. Disponível em: https://doi.org/10.20396/rdbci.v16i2.8650461. Acesso em: 2 set. 2020.

BORBA, Mayla Gabriela S. et al. Chloroquine diphosphate in two different dosages as adjunctive therapy of hospitalized patients with severe respiratory syndrome in the context of coronavirus (SARS-CoV-2) infection: preliminary safety results of a randomized, doubleblinded, phase IIb clinical trial (CloroCovid-19 Study). MedRxiv. 2020. Disponível em: https://www.medrxiv.org/content/10.1101/2020.04.07.20056424v2 . Acesso em: 10 set. 2020.

CHIARELLI, Andrea; JOHNSON, Rob; PINFIELD, Stephen; RICHENS, Emma. Preprints and Scholarly Communication: an exploratory qualitative study of adoption, practices, drivers and barriers. F1000Research, v.8, n. 971, 2019. Disponível em: https://doi.org/10.12688/f1000research.19619.2. Acesso em: 15 set. 2020.

CIENTISTAS que pesquisam cloroquina sofrem ameaças de morte no AM. Catraca Livre, 17 abr. 2020. Disponível em: https://catracalivre.com.br/saude-bem-estar/cientistas-quepesquisam-cloroquina-sofrem-ameacas-de-morte-no-am/. Acesso em: 10 set. 2020.

DIAS, Ricardo Henrique Almeida; ALMEIDA, Maria José P.M. de. Especificidades do jornalismo científico na leitura de textos de divulgação científica por estudantes de licenciatura em física. Rev. Bras. Ensino Fís., São Paulo, v. 31, n. 4, p. 4401-4412, dez. 2009. Disponível em: http://www.scielo.br/scielo.php?script=sci_arttext\&pid=S1806$11172009000400013 \& \operatorname{lng}=e n \& n r m=$ iso. Acesso em: 28 set. 2020.

EPSTEIN, Isaac. Comunicação da ciência: rumo a uma teoria da divulgação científica Autores. Organicom, v. 9, n. 16-17, p. 19-38, 2012. Disponível em: http://www.revistas.usp.br/organicom/article/view/139126/134478. Acesso em: 29 ago. 2020. 
FISHMAN, Mark. Manufacturing the news. Austin: University of Texas Press, 1980.

GITLIN, Todd. The whole world is watching: mass media in the making and unmaking of the new left. Univ. of California Press, 2003.

GRANCHI, Giulia. Bolsonaro e Teich discordam sobre cloroquina: o que dizem os estudos? UOL, São Paulo, 15 maio 2020. Viva Bem. Disponível em:

https://www.uol.com.br/vivabem/noticias/redacao/2020/05/15/bolsonaro-e-teich-discordamsobre-cloroquina-o-que-dizem-os-estudos.htm?cmpid=copiaecola. Acesso em: 10 set. 2020.

GRAGNANI, Juliana. Coronavírus: o que dizem os estudos publicados sobre cloroquina, defendida por Bolsonaro e Trump. UOL, São Paulo, 19 maio 2020. Viva Bem. Disponível em: https://www.uol.com.br/vivabem/noticias/bbc/2020/05/19/coronavirus-o-que-dizem-osestudos-publicados-sobre-cloroquina-defendida-por-bolsonaro-etrump.htm?cmpid=copiaecola. Acesso em: 10 set. 2020.

HART, P. Sol; CHINN, Sedona; SOROKA, Stuart. Politicization and Polarization in COVID19 News Coverage. Science Communication, Sage Journals, 25 Aug., 2020.

https://journals.sagepub.com/doi/full/10.1177/1075547020950735. Acesso em: 10 set. 2020.

INGRID, Gabriela. Nise Yamaguchi interpreta estudos de forma errada para defender cloroquina. UOL, São Paulo, 18 maio 2020. Viva Bem. Disponível em:

https://www.uol.com.br/vivabem/noticias/redacao/2020/05/18/medica-que-defende-

cloroquina-interpreta-estudos-de-forma-errada.htm?cmpid=copiaecola. Acesso em: 7 set. 2020 .

JOHNSON, R. Burke; ONWUEGBUZIE, Anthony J.; TURNER, Lisa A. Toward a definition of mixed methods research. Journal of mixed methods research, v. 1, n. 2, p. 112-133, 2007. Disponível em: https://journals.sagepub.com/doi/10.1177/1558689806298224. Acesso em: 2 set. 2020.

LUTHER, Judy; ANDERSON, Ivy; BRADFORD, Monica; INGLIS, John. Preprints, institutional repositories, and the version of record, 2017. Proceedings of the Charleston Library Conference. Disponível em: http://dx.doi.org/10.5703/1288284316717. Acesso em: 10 set. 2020 .

MONARI, Ana Carolina; SANTOS, Allan; SACRAMENTO, Igor. COVID-19 and (hydroxy) chloroquine: a dispute over scientific truth during Bolsonaro's weekly Facebook live streams. Journal of Science Communication, v. 19, n. 7, p. A03, 2020. Disponível em: https://jcom.sissa.it/sites/default/files/documents/JCOM_1907_2020_A03.pdf. Acesso em: 2 set. 2020.

OLIVEIRA, Thaiane Moreira de. Como enfrentar a desinformação científica? Desafios sociais, políticos e jurídicos intensificados no contexto da pandemia. Liinc em Revista, v. 16, 
n. 2, p. e5374-e5374, 2020. Disponível em: http://revista.ibict.br/liinc/article/view/5374/5123. Acesso em: 03 set. 2020.

O QUE SE SABE sobre o uso de cloroquina contra o coronavirus. Catraca Livre, 15 abr. 2020. Disponível em: https://catracalivre.com.br/saude-bem-estar/o-que-se-sabe-ate-agorasobre-o-uso-de-cloroquina-contra-o-coronavirus/. Acesso em: 10 set. 2020.

ORGANISATION FOR ECONOMIC CO-OPERATION AND DEVELOPMENT (OECD). Why Open science is critical to combating COVID-19. 12 May 2020. Disponível em: https://www.oecd.org/coronavirus/policy-responses/why-open-science-is-critical-tocombatting-covid-19-cd6ab2f9/. Acesso em: 10 set. 2020.

ORTEGA, Jose Luis. Blogs and news sources coverage in altmetrics data providers: a comparative analysis by country, language, and subject. Scientometrics, v. 122, p. 555-572, 2020. Disponível em: https://link.springer.com/article/10.1007\%2Fs11192-019-03299-2. Acesso em: Acesso em: 10 set. 2020.

PESQUISA brasileira não usou doses de cloroquina para matar pacientes. Uol, 24 abr. 2020. Disponível em: https://noticias.uol.com.br/comprova/ultimas-noticias/2020/04/24/pesquisabrasileira-nao-usou-doses-de-cloroquina-para-matar-pacientes.htm?cmpid=copiaecola. Acesso em: Acesso em: 10 set. 2020.

PESQUISADORES interrompem estudo com cloroquina após mortes de pacientes. Catraca Livre, 14 abr. 2020. Disponível em: https://catracalivre.com.br/saude-bemestar/pesquisadores-interrompem-estudo-com-cloroquina-apos-mortes-de-pacientes/. Acesso em: 10 set. 2020.

PUBLIC Health Emergency COVID-19 Initiative. Mar. 2020. Disponível em: https://www.ncbi.nlm.nih.gov/pmc/about/covid-19/. Acesso em: 10 set. 2020.

PUBMED OVERVIEW. National Library of Medicine, [s.d]. Disponível em: https://pubmed.ncbi.nlm.nih.gov/about/. Acesso em: 13 set. 2020.

SCHÄFER, Mike S.; KRISTIANSEN, Silje; BONFADELLI Heinz.

Wissenschaftskommunikation im Wandel [eBook]. Köln: Herbert von Halem Verlag, 2015.

SCHÄFER, Mike S.; KESSLER, Sabrina Heike; FÄHNRICH, Birte. Analyzing science communication through the lens of communication science: reviewing the empirical evidence. Science communication, p. 77-104, 2019.

SHARING research data and findings relevant to the novel coronavirus (COVID-19) outbreak. Welcome, 30 Jan. 2020. Disponível em: https://wellcome.org/press-release/sharingresearch-data-and-findings-relevant-novel-coronavirus-ncov-outbreak. Acesso em: 12 set. 2020. 
SCIENCE-METRIX. Analytical Support for Bibliometrics Indicators Open access availability of scientific publications. Canadá, 2018.

TADDICKEN, Monika; WOLFF, Laura. 'Fake News' in Science Communication: Emotions and Strategies of Coping with Dissonance Online. Media and Communication, v. 8, n. 1, p. 206-217, 2020.

TAVARES, Camilla Quesada. O papel político do jornalismo: as "convicções" da Gazeta do Povo e a produção da notícia. Revista Compolítica, vol. 10, n. 2, 2019. Disponível em: http://ctpol.unb.br/compolitica2019/GT8/gt8_Tavares.pdf. Acesso em: 10 set. 2020.

THE GLOBAL pandemic has renewed trust in science. State of science index survey, $\mathbf{3 M}$, 2019. Disponível em: https://www.3m.com/3M/en_US/state-of-science-index-survey/about2019-survey/. Acesso em: 6 set. 2020.

THE WHITE HOUSE/ Office of Science and Technology Policy. President Trump's Science Advisor and Government Science Leaders from Around the World call on Publishers to make all COVID-19-Related Research Publically. Washington DC, White House, 2020. Disponível em: http://listserv.crl.edu/wa.exe?A2=LIBLICENSEL;23fe98a3.2003\&amp;FT=\&amp;P=\&amp;H=\&amp;S=. Acesso em: 10 set. 2020.

TUCHMAN, Gaye. Making news: a study in the construction of reality. New York: Free Press, 1978.

VERAS, Thor João de Souza. Negacionismo viral e política exterminista: notas sobre o caso brasileiro da COVID-19. Voluntas: Revista Internacional de Filosofia, v. 11, p. 1-13, 2020.

WEINGART, Peter; GUENTHER, Lars. Science communication and the issue of trust. Journal of science communication. v. 15, n. 5, 2016. URL: http://jcom.sissa.it/archive/15/05/JCOM_1505_2016_C00/JCOM_1505_2016_C01. Acesso em: 13 set. 2020.

WELLCOME. Sharing research data and findings relevant to the novel coronavirus (COVID19) outbreak. Organisation for Economic Co-Operation and Development, 30 Jan. 2020. Disponível em: https://wellcome.org/press-release/sharing-research-data-and-findingsrelevant-novel-coronavirus-ncov-outbreak. Acesso em: 10 set. 2020.

YOUNG, Cory; SIMMONS, Hunter; STEWART, Margaret. Social listening during crises: a practitioner guide for crisis communication on social media. In: Proceedings of the international crisis and risk communications conference, 11-13 Mar. 2019, Orlando FL, USA, 2019. Disponível em: https://stars.library.ucf.edu/cgi/viewcontent.cgi?article=1039\&context=icrcc. Acesso em: 12 set. 2020.

ZANETTI, Daniela; REIS, Ruth. Comunicação e informação num contexto de pandemia e isolamento social. Vitória: UFES, 2020. Disponível em: 
https://www.ufes.br/sites/default/files/anexo/comunicacao_coronavirus-ufes.pdf. Acesso em: 07 set. 2020.

Submetido em: 07.10.2020.

Aprovado em: 10.12.2020. 